OPEN ACCESS

Edited by:

Wim Ceelen,

Ghent University,

Belgium

Reviewed by:

Paul Willemsen,

ZNA, Belgium

Wouter Willaert,

Ghent University, Belgium

*Correspondence:

Hassan Adwan

hassan.adwan@guc.edu.eg

Specialty section: This article was submitted to Surgical Oncology, a section of the journal

Frontiers in Oncology

Received: 28 February 2017 Accepted: 27 June 2017

Published: 18 July 2017

Citation:

Adwan H, Georges R, Pervaiz A and Berger MR (2017) Investigation of

Metastasis-Related Genes: A Rat Model Mimicking Liver Metastasis of

Colorectal Carcinoma.

Front. Oncol. 7:152.

doi: 10.3389/fonc.2017.00152

\section{Investigation of Metastasis-Related Genes: A Rat Model Mimicking Liver Metastasis of Colorectal Carcinoma}

\author{
Hassan Adwan ${ }^{1 *}$, Rania Georges ${ }^{2}$, Asim Pervaiz $^{3}$ and Martin R. Berger ${ }^{2}$ \\ ' Faculty of Pharmacy and Biotechnology, Department of Pharmacology and Toxicology, The German University in Cairo, \\ Cairo, Egypt, ${ }^{2}$ Toxicology and Chemotherapy Unit, German Cancer Research Center, Heidelberg, Germany, ${ }^{3}$ Department of \\ Allied Health Sciences, University of Health Sciences, Lahore, Pakistan
}

Liver is the main target of colorectal cancer (CRC) metastasis. Currently, the number of reports is small, which describe changes in gene expression supporting liver metastasis. Here, a rat model was used for analyzing mRNA modulations during liver colonization and compared with available literature. In the model, CC531 rat CRC cells were injected via a mesenteric vein into isogenic WAG/Rij rats and re-isolated at early, intermediate, advanced, and terminal stages of liver colonization. These cells were used for RNA isolation. Microarrays were used for analyzing mRNA profiles of expression. The number of deregulated genes is comparatively large and only part of it has been studied so far. As reported to date, claudins and insulin-like growth factor-binding proteins (IGFBPs) were found to be deregulated. The fact that the chosen method is efficient is confirmed by the study of claudins and IGFBPs, which show altered expression in the initial stages of liver colonization and then return to normalcy. In addition, cadherin was described to be downregulated in epithelial-mesenchymal transition models. It can, therefore, be concluded that the models used are helpful in finding genes, which are instrumental for metastatic liver colonization.

\section{Keywords: animal models, liver metastases, tumor progression, colorectal cancer, metastasis-related genes}

\section{INTRODUCTION}

With more than one million new cases, colorectal cancer (CRC) is one of the most common malignancies worldwide (1). In the primary operative treatment of CRC, metastasis is the limiting parameter. The progress of a CRC is also characterized by increased primary carcinoma growth and hematogenic and lymphatic spread. However, at the time of diagnosis, up to $25 \%$ of patients have a synchronous hematogenic metastasis, which is most frequently manifested in the liver. After resection of the primary tumor, a similar percentage (up to $25 \%$ ) of the patients develops metastasis in the subsequent course of the disease, i.e., within the next 3 years (metachronous type of progression) $(2-4)$. Surgery is only possible for a small proportion of these patients (about $10 \%$ ). For the other patients, survival is limited to only 9-19 months (2-6).

When seeking explanations, why the liver is a main target of colorectal cancer metastasis, anatomical reasons are most often discussed. The liver represents the first capillary bed, in which disseminated colorectal cancer cells can become stuck. Subsequently, they grow and form lifethreatening metastases, which are reason for the aggressive behavior and resulting mortality of CRC (5-7). Treatment of these metastases is rarely curative, if conventional surgery, radiotherapy, and chemotherapy are being used (8). 
The primary tumors consist of a heterogeneous population of cells that are genetically distinct. This genetic variability allows the tumor cells to separate from the primary tumor and overcome various obstacles before growing in other organs. Nevertheless, only an extremely small part $(0.001 \%)$ of disseminated tumor cells can form metastases $(9,10)$. This observation indicates that many aspects of the metastatic process are still unclear. Nevertheless, some of the sub-mechanisms are considered to be scientifically well explored. The metastatic process can be divided into three main processes, namely the initialization process, the progression process, and the establishment process. In order to develop a malignant and progressively metastasizing cell from a normal mucosal cell, many characteristics are necessary, which enable the cells to grow autonomously, continuously, and invasively $(11,12)$.

\section{ANIMAL MODELS FOR LIVER METASTASIS}

Typically, models should mimic the characteristics of the disease, which is to be investigated. Some animal models have been developed to mimic CRC and its progression. Most frequently, human tumor cells were transplanted subcutaneously into nude rodents (so-called xenografts), as the respective tumor growth in this model can easily be measured. However, the value of these models has been questioned, especially when it comes to assessing the efficacy of new drugs, because these tumors are normally non-invasive and do not form metastases.

Pending on the origin of tumor cells, transplantation models can be isogenic or xenograft models. In the case of isogenic models, usually mouse or rat tumor cell lines are used. In xenograft transplantation models, human tumor cells or human tumor pieces are injected and implanted into immune-incompetent (nude) animals. Orthotopic cancer models are based on the implantation of cancer cells into the organ, from which the tumor cells originated. In the majority of these models, however, tumor growth cannot be assessed by eye. With regard to xenografts, it was observed that the produced tumors are histologically a mixture of human tumor cells and murine stromal cells (13).

An example of a transplanted isogenic model is the rat colorectal cancer cell line CC531, which was originally developed from a colon cancer growing in a dimethyl hydrazine-induced WAG/ Rij rat (14). This tumor grew in various organs, including lymph nodes, abdominal cavity, and liver (15). For a considerable time, this property was used to evaluate the efficacy and toxicity of new antineoplastic treatment modalities (e.g., drugs, irradiation, antibodies, photodynamic therapy, locoregional administration) in experimental liver metastasis (16-27).

However, this model suffered from its growth in organs, which could not be inspected regularly. Therefore, markers were introduced, which were to help in monitoring the growth of this tumor. Accordingly, CC531 cells were marked with genes that facilitate their detection, as well as their interaction with the environment. Examples of such marker genes are the Escherichia coli $\beta$-galactosidase (lacZ) gene (28). The exposure of cells, which are transfected with this gene, to X-Gal (5-Bromo-4-chloroindoxyl- $\beta$-D-galactopyranoside), leads to cleavage of this substrate into galactose and 5-bromo4-chloro-indoxyl. The latter dye is air-dried to the blue dye 5,5-dibromo-4,4-dichloroindigo. The lacZ gene is considered a stable marker during tumor progression in vivo (28-37). Transfection of CC531 cells by the lacZ gene was performed by Wittmer et al. (38) and the resulting clone was used for determining the tumor load of the animals at the end of the respective experiments (39-45).

Green fluorescence protein (GFP) and its variants are also markers that allow the detection and sorting of tumor cells by using certain light wavelengths and fluorescence activated cell sorting (FACS) analysis, respectively (46-48).

Similar to the lacZ method, the luciferase reporter system is an alternative that enables an optical detection of tumor cells in vitro and in vivo $(49,50)$. In transfected tumor cells, the luciferase gene is stably expressed, resulting in the presence and activity of the luciferase enzyme. Exposure of these cells to the respective substrate (luciferin, coelenterazine) results in light emission, which can be directly measured and correlated to the size of the tumor (51). Both markers, enhanced GFP and luciferase, were introduced into CC531 cells to allow improved detection during the lifespan of the animals $(47,52)$.

This final model was used most recently to identify new genes that are involved in the early stage of rat liver metastasis $(47,52)$.

The respective experiments, detailing the re-isolation of CC531 cells, being stably transfected with GFP as well as luciferase genes, from rat liver at various stages of colonization are detailed in the subsequent review. The aim of these experiments was to describe the genetic characteristics of liver-metastasis as a selfregulating process, which has features that are independent from the primary tumor. So far, this question has not been sufficiently covered in the literature, although related work, which focused on the isolation of tumor nodules, was done by Velthuis et al. (44), Sun et al. (45), Georges et al. (53), and Speetjens et al. (54).

Specifically, the question was addressed, which temporal profile of gene expression tumor cells must show to enable their growth and metastasis in the liver. In view of the enormous genetic diversity of the primary tumor and the high number of disseminated tumor cells in the venous blood of carcinomas, this approach did not focus on cells obtainable by liquid biopsy, but used the liver as filter for those cells, which are able to form liver metastases. Consequently, the entire period of the metastatic colonization of the liver was investigated. It was hoped that the changes in gene expression detected in re-isolated tumor cells would be helpful in understanding the mechanism of action of liver colonization by CRC cells, as well as for finding a specific therapy.

\section{PREPARATION AND INJECTION OF CC531 CELLS}

Six- to eight-week-old male WAG/Rij rats with a body weight of 160-180 g were purchased from Charles River, Sulzfeld, Germany. The rats were kept and anesthetized as previously described $(38,47,55)$. All animal experiments were approved by the responsible governmental animal ethics committee (Regierungspraesidium Karlsruhe, Germany). Logarithmically growing CC531 cells were prepared at a concentration of 
$4-8 \times 10^{6}$ cells $/ 500 \mu \mathrm{l}$ depending on the experiment. After opening the abdomen, the cecum with its adjacent mesenteric vein was appropriately placed to allow the insertion of a $30 \mathrm{G}$ needle (BD, Heidelberg, Germany). Four hundred microliters of CC531 cell suspension was injected at a distance of $\sim 1-1.5 \mathrm{~cm}$ from the cecum. The needle was gently inserted into the vein and the inoculation was administered slowly and lasted for 2-3 min, in order to achieve a good distribution of the cells in all liver lobes (Figures 1 and 2).

\section{RE-ISOLATION OF HEPATOCYTES, KUPFFER CELLS, AND TUMOR CELLS FROM THE RAT LIVER}

Ten rats (2 for each time point; i.e., 3, 6, 9, 14, and 21 days after tumor cell inoculation) were sacrificed and used for the experiment described below. It is also worth noting that all animals survived the experiment. An incision was made into

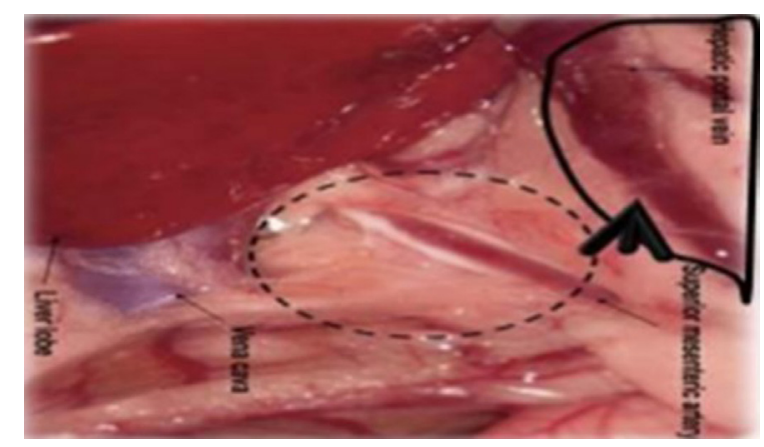

FIGURE 1 | Schematic illustration of the injection site. The CC531 rat CRC cells were inoculated into the mesenteric vein to form liver metastasis. the abdominal wall and the intestines were placed out of the abdominal cavity to locate the portal vein (Figure 1). The liver was washed and connection tissues were digested as described previously $(47,52,53,56)$. Subsequently, the liver was excised from the rat and placed into a sterile Petri dish. The liver was then treated with an appropriate enzyme cocktail (pronase and collagenase Type IV) and the resulting cell suspension of liver and tumor cells was transferred into tubes and layered carefully onto a Ficoll gradient medium. After centrifugation (15 min at $500 \times g$ ), hepatocytes, Kupffer cells, and tumor cells were obtained from the different layers of the interface (Figure 2). For better detection and to gain a high purity of isolated tumor cells, tumor cells were beforehand stably transfected with red fluorescence protein (RFP; Figure 3) and luciferase (Figure 4).

\section{GENE EXPRESSION PROFILE OF THE RE-ISOLATED CELLS}

From the genes analyzed by microarray, some genes, which were $\geq 2$-fold up- or downregulated when compared to control cells, were chosen for subsequent analysis in vitro and in human CRC specimens.

\section{Claudins}

The aim of this experiment was to determine changes in the expression profile of the CRC cells during their colonization of the rat liver in order to determine a specific, time-dependent modification of metastasis-relevant genes and processes for further studies. The mRNA of the re-isolated cells was used in cDNA microarrays to analyze the mRNA expression profiles of these cells during their growth in the rat liver. During liver colonization, claudins 1 and 4 showed two-phase changes in their expression, in correlation with their presumed function during liver colonization. Initially, a significant reduction in the expression

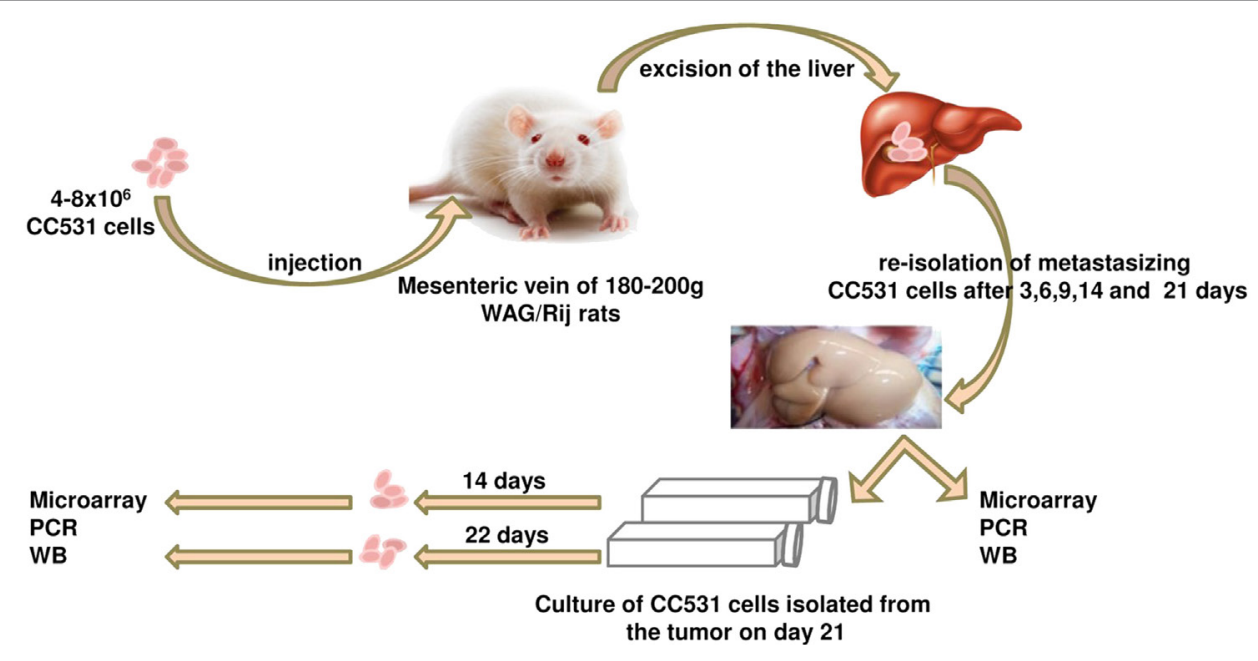

FIGURE 2 | Schematic illustration of the tumor cells' isolation experiment. The CC531 rat CRC cells are injected into the rat liver and re-isolated after different time periods $(3,6,9,14$, and 21 days). Cells isolated after 21 days were cultured for further 14 and 22 days in vitro. Proteins and mRNA were isolated from all cells for Western blot, as well as PCR and microarray, respectively. 


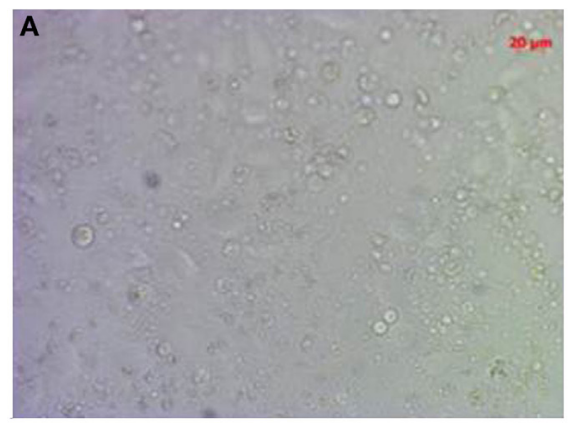

re-isolated CC531 cells after $5 \mathrm{~h}$ of isolation

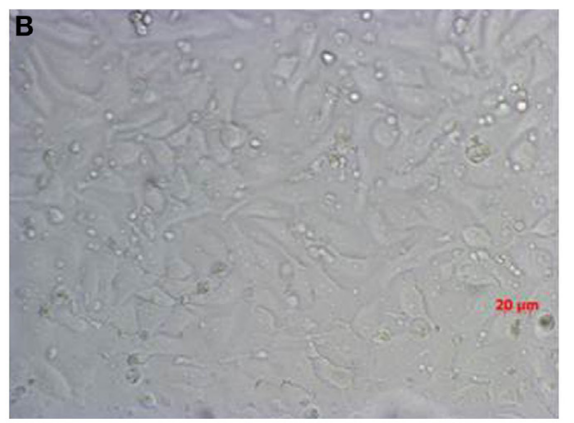

re-isolated CC531 cells after $30 \mathrm{~h}$ of isolation

FIGURE 3 | CC531 rat CRC cells re-isolated from rat liver after 6 days of tumor cells' inoculation. (A,B) Microscopic photographs of CC531 cells after 5 and 30 h of their re-isolation from rat liver. Magnification $\times 200$, the bars indicate a distance of $20 \mu \mathrm{m}$.
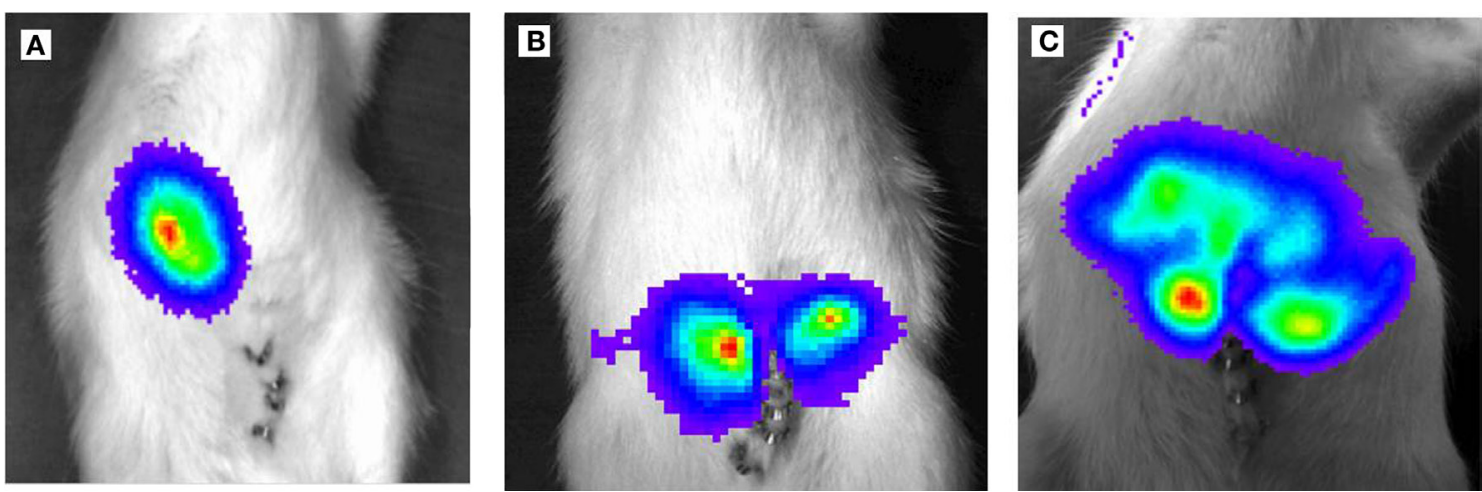

FIGURE 4 | Light emission based on luciferase activity of CC531 RFP-LUC rat CRC cells, $5 \times 10^{5}$ CC531 RFP-LUC cells were injected into the rat liver. Aspect after luciferin injection of tumor bearing animals. (A) 14 days following transplantation of CC531 ${ }^{\text {RFP-LUC }}$ cells. (B) 21 days following transplantation of CC531 RFP-LUC cells. (C) 28 days following transplantation of CC531 $1^{\text {RFP-LUC }}$ cells.

of claudins (here: claudin 1 and claudin 4) was observed, which were up to eightfold reduced compared to the control (Table 1). To analyze whether this reduced expression is primarily due to contact with the new environment, a coculture of the tumor cells with isolated rat hepatocytes and Kupffer cells was carried out. However, no change in the expression of the affected claudins was observed. However, the expression of claudin 4 was increased when the shear and friction forces in the blood circulation were simulated experimentally. A reduction in the mRNA expression of claudins 1 and 4 by siRNA caused a significantly increased migration and at the same time reduced the colony formation capacity of the tumor cells $(P<0.05)$, but had no effect on their proliferative capacity (47).

An investigation of human CRC samples showed increased expression of claudins 1 and 4 by immunohistochemistry in stages I-III carcinomas, but at stage IV and in liver metastases, claudin expression was significantly reduced $(P<0.05)$. In addition, it was shown that an increased claudin 4 expression was correlated with a significantly reduced overall survival (log rank test, $P=0.018)(47)$.
TABLE 1 | Comparative expression of some genes, including adhesion molecules, insulin-like growth factor-binding proteins (IGFBPS), and chemokines.

\begin{tabular}{llr} 
Gene family/genes & Gene expression & Reference \\
\hline $\begin{array}{ll}\text { Adhesion molecules } \\
\text { Cldn1 }\end{array}$ & Downregulated in early metastasis & $(47)$ \\
Cldn4 & Downregulated in early metastasis & $(47)$ \\
E-cadherin & Downregulated in epithelial- \\
& mesenchymal transition (EMT) \\
IGFBPs & Upregulated in early metastasis \\
lgfbp3 & Upregulated in early metastasis \\
Igfbp7 & & \\
Chemokines & Upregulated in early metastasis \\
Ccr1 & Upregulated in early metastasis & \\
Ccrl2 & & \\
\hline
\end{tabular}

\section{The Insulin-Like Growth Factor-Binding Proteins (IGFBPs) 3 and 7 Are Associated with Liver Metastasis of Colorectal Cancer} In a follow-up experiment, the family of IGFBPs was investigated more closely. Some members of this family also showed a highly 
significant change in their expression in the micro-array examination after re-isolation of CC531 rat CRC cells from rat liver. In contrast to the expression of the claudins, the expression of IGFBPs was initially significantly increased and normalized later, with the progressive infiltration of the liver by the tumor cells. IGFBP3 and 7, which represent the main group of IGFBPs and the side group of the related proteins, were selected from the group as a whole. A knockdown of both proteins resulted in reduced proliferation, colony formation, and migration (the latter only IGFBP3) of the CC531 cells.

In human tumor samples, expression of both genes was higher in UICC stages II and III than in stages I and IV. In addition, IGFBP3 was negatively correlated to the age of the affected patients in these samples and positively correlated with the expression of IGFBP7 (52).

\section{Role of Chemokines and Their Receptors in CRC Progression}

The chemokines C-C chemokine receptor type 1 (CCR1) and C-C motif receptor-like 2 (CCRL2) are associated with colorectal cancer liver metastasis: The expression modulation of CCR1 and chemokine CCRL2 were investigated in the same rat liver metastasis model. In addition, their expression in rat and human CRC samples was also analyzed. In this experiment, we studied the effects of their knockdown on cellular properties in a panel of colorectal cancer cell lines. One rat and five human colorectal cancer cell lines were used for this purpose.

All cell lines were screened for mRNA expression of CCR1 and CCRL2 by reverse transcription polymerase chain reaction (RT-PCR). Cell lines with detectable expression were further investigated. Specifically, the cells' proliferation, scratch closure, and colony formation was determined, respectively. Knockdown of the two genes resulted in modest but significant inhibition of proliferation $(P<0.05)$, scratch closure, and colony formation $(P<0.05)$.

The re-isolation of CC531 rat colorectal cells from rat livers after defined periods, followed by mRNA isolation, showed a clear modulation in the expression profile of these genes during the colonization process. In particular CCRL2 and CCR1 were upregulated 27 and 4 times, respectively, when compared with the control cells.

Finally, specimens from 50 patients with CRC were examined by quantitative RT-PCR for CCR1 and CCRL2 expression levels. All human CRC samples were positive for CCR1 and CCRL2 and showed a significant pairwise correlation $(P<0.0004)$, but there was no correlation with tumor stage or age of patients (61).

The chemokine receptor CCR5 was found to be increased in CC531 cells in a way similar to CCR1 and CCRL2. To investigate its importance, CCR5 (CD195) was blocked with the CCR5 receptor antagonist maraviroc in human colorectal carcinoma cells (SW480 and SW620). Subsequently, the effect of this blockade on the cell properties and the associated signal paths were examined. The blockade with maraviroc caused a significant proliferation inhibition and a marked arrest of the cells in phase G1 of the cell cycle. In addition, maraviroc caused a significant increase in apoptosis induction at the morphological level. Concomitantly, a significant modulation of several apoptosis-relevant genes was observed at the mRNA level and activation (posttranslational modification) of the caspases was observed at the protein level. The observations were depicted in a signaling pathway of CCR5, which summarizes the cytotoxic and apoptotic effects of maraviroc in colorectal carcinoma cells (62).

\section{The Regulation of Osteopontin and Functionally Associated Genes in the CC531 Model In Vitro and In Vivo}

The expression of the matrix protein osteopontin, as well as that of osteopontin associated genes BSP II, Runx2, Hoxc8, MMP-7, and MMP-9 was also studied in CC531 cells during the colonization process and in vitro.

OPN, Runx2, and MMP-7 showed increased expression in the advanced stage of liver metastasis but subsequently showed reduced expression after the isolated tumor cells had been further cultured in vitro. In addition, an inverse regulation of Hoxc8, OPN, and Runx2 was observed. The cocultivation of the tumor cells with hepatocytes did not cause increased expression of OPN and RUNX2, whereas the addition of TGF- $\beta 1$ induced overexpression of OPN and Runx 2 in tumor cells but not in cocultured hepatocytes $(52,63)$.

\section{DISCUSSION}

The pathophysiologic consequences of gastrointestinal cancers' metastases are a major cause of their mortality $(2,64,65)$. After a large number of studies, tumors are genetically derived from heterogeneous cell aggregates (3, 66-68). Despite this genetic heterogeneity, individual disseminated tumor cells often follow the same pattern of metastasis formation. They grow initially in the liver, but not, or only in the further course, in other organs $(10,69,70)$.

In addition, only a small fraction of the disseminated tumor cells succeed in forming metastases. In line with this, it must be borne in mind that disseminated tumor cells are not true metastases, but represent only tumor cells with a necessary but not sufficient precondition to metastasize. From their enormous number and high genetic heterogeneity/diversity, the real metastases are recruited (71).

One of the questions that have remained unanswered so far is what genetic characteristics these individual metastasisproducing cells have and how it is possible to identify them in the face of the enormous genetic diversity of the primary tumor and the large number of cells that separate from it? Morphological and genetic examinations of established metastases generally do not provide any clue since morphological aspects and genetic signatures differ only slightly in terms of mutations in tumor suppressor and oncogenes from the primary tumor (3).

Rather, identification of modulated gene expression, even if present for a short time only, would possibly allow inhibiting the metastasis process by means of targeted manipulations.

Therefore, the aim of this work was to analyze the literature regarding expression profiles of tumor cells during the entire period of metastatic colonization of the liver, in order to 
manipulate them in a targeted manner. For the main part of this review, a CRC tumor model was considered, which mimics the metastasis process. This model is based on CC531 rat -CRC cells, which were injected via the mesenteric vein into the liver of WAG/Rij rats and then re-isolated after various times (55). For an analysis of the genetic profile, a pure cell population is essential. In order to ensure this, two enrichment methods were used, i.e., a Ficoll gradient followed by FACS, which was based on the CC531 cells' labeling with the marker protein RFP.

The mRNA expression profile of these cells was investigated during the entire liver-colonization process. Interestingly, genes were activated or deactivated at the beginning of the colonization process, and this alteration was related to the process progression.

With regard to the type of modulation, claudins and E-cadherin were found to be decreased, whereas the insulin-like growth factor binding proteins and chemokines showed increased expression. Notably, these modulations normalized later again.

For the claudins and E-cadherin, their diminished expression is an indication of the so-called epithelial-mesenchymal transition (EMT). This is in accord with the EMT theory, which states that in metastasizing tumor cells a phenotype change must first take place. These cells lose their adhesion properties and gain the

\section{REFERENCES}

1. Lozano R, Naghavi M, Foreman K, Lim S, Shibuya K, Aboyans V, et al. Global and regional mortality from 235 causes of death for 20 age groups in 1990 and 2010: a systematic analysis for the Global Burden of Disease Study 2010. Lancet (2012) 380:2095-128. doi:10.1016/S0140-6736(12)61728-0

2. Adam R, Lucidi V, Bismuth H. Hepatic colorectal metastases: methods of improving resectability. Surg Clin North Am (2004) 84:659-71. doi:10.1016/j. suc.2003.12.005

3. Nguyen DX, Bos PD, Massague J. Metastasis: from dissemination to organ-specific colonization. Nat Rev Cancer (2009) 9:274-84. doi:10.1038/ nrc2622

4. Rudmik LR, Magliocco AM. Molecular mechanisms of hepatic metastasis in colorectal cancer. J Surg Oncol (2005) 92:347-59. doi:10.1002/jso.20393

5. Cunningham D, Atkin W, Lenz HJ, Lynch HT, Minsky B, Nordlinger B, et al. Colorectal cancer. Lancet (2010) 375:1030-47. doi:10.1016/S01406736(10)60353-4

6. Meyerhardt JA, Mayer RJ. Systemic therapy for colorectal cancer. N Engl J Med (2005) 352:476-87. doi:10.1056/NEJMra040958

7. Leber MF, Efferth T. Molecular principles of cancer invasion and metastasis (review). Int J Oncol (2009) 34:881-95. doi:10.3892/ijo_00000214

8. Dong F, Budhu AS, Wang XW. Translating the metastasis paradigm from scientific theory to clinical oncology. Clin Cancer Res (2009) 15:2588-93. doi:10.1158/1078-0432.CCR-08-2356

9. Fidler IJ. Critical determinants of metastasis. Semin Cancer Biol (2002) 12:89-96. doi:10.1006/scbi.2001.0416

10. Gavrilovic IT, Posner JB. Brain metastases: epidemiology and pathophysiology. J Neurooncol (2005) 75:5-14. doi:10.1007/s11060-004-8093-6

11. Hanahan D, Weinberg RA. The hallmarks of cancer. Cell (2000) 100:57-70. doi:10.1016/S0092-8674(00)81683-9

12. Hanahan D, Weinberg RA. Hallmarks of cancer: the next generation. Cell (2011) 144:646-74. doi:10.1016/j.cell.2011.02.013

13. Khanna C, Hunter K. Modeling metastasis in vivo. Carcinogenesis (2005) 26:513-23. doi:10.1093/carcin/bgh261

14. Marquet RL, Westbroek DL, Jeekel J. Interferon treatment of a transplantable rat colon adenocarcinoma: importance of tumor site. Int J Cancer (1984) 33:689-92. doi:10.1002/ijc.2910330521

15. Marinelli A, Dijkstra FR, Van Dierendonck JH, Kuppen PJ, Cornelisse CJ, Van De Velde CJ. Effectiveness of isolated liver perfusion with mitomycin C ability to migrate. The loss of cell adhesion is caused, inter alia, by reduced expression of adhesion molecules such as claudines and E-cadherin (57-60).

During the colonization process, IGFBPs and chemokines showed a contrasting expression pattern (see Table 1).

\section{CONCLUSION}

This review focusses on animal models, which identified genes that are modulated in their expression during liver colonization by CRC cells. The number of these genes is comparatively large and only a part of it has been identified so far. Nevertheless, the chosen method is efficient as is shown by the results on claudins, E-cadherin, insulin-like growth factor-related proteins, and chemokines, which show distinct modulation of expression during liver colonization. Such findings may contribute to exploiting the potential of these genes as suitable markers for early diagnosis or as targets of an effective therapy of liver metastasis.

\section{AUTHOR CONTRIBUTIONS}

$\mathrm{HA}$ is the main author. RG and AP have prepared the figures. MB reviewed the publication.

in the treatment of liver tumours of rat colorectal cancer. Br J Cancer (1991) 64:74-8. doi:10.1038/bjc.1991.242

16. Eggermont AM, Marquet RL, De Bruin RW, Jeekel J. Effects of the interferoninducer ABPP on colon cancer in rats; importance of tumor load and tumor site. Cancer Immunol Immunother (1986) 22:217-20. doi:10.1007/ BF00200036

17. Marquet RL, Ijzermans JN, De Bruin RW, Fiers W, Jeekel J. Anti-tumor activity of recombinant mouse tumor necrosis factor (TNF) on colon cancer in rats is promoted by recombinant rat interferon gamma; toxicity is reduced by indomethacin. Int J Cancer (1987) 40:550-3. doi:10.1002/ ijc. 2910400419

18. Los G, Mutsaers PH, Ruevekamp M, Mcvie JG. The use of oxaliplatin versus cisplatin in intraperitoneal chemotherapy in cancers restricted to the peritoneal cavity in the rat. Cancer Lett (1990) 51:109-17. doi:10.1016/0304-3835 (90)90045-Y

19. Los G, Ruevekamp M, Bosnie N, De Graaf PW, Mcvie JG. Intraperitoneal tumor growth and chemotherapy in a rat model. Eur J Cancer Clin Oncol (1989) 25:1857-66. doi:10.1016/0277-5379(89)90359-3

20. van Hillegersberg R, Marijnissen JP, Kort WJ, Zondervan PE, Terpstra OT, Star WM. Interstitial photodynamic therapy in a rat liver metastasis model. Br J Cancer (1992) 66:1005-14. doi:10.1038/bjc.1992.402

21. van Eijck CH, Slooter GD, Hofland LJ, Kort W, Jeekel J, Lamberts SW, et al. Somatostatin receptor-dependent growth inhibition of liver metastases by octreotide. Br J Surg (1994) 81:1333-7. doi:10.1002/bjs.1800810925

22. Veenhuizen RB, Marijnissen JP, Kenemans P, Ruevekamp-Helmers MC, 't Mannetje LW, Helmerhorst TJ, et al. Intraperitoneal photodynamic therapy of the rat CC531 adenocarcinoma. Br J Cancer (1996) 73:1387-92. doi:10.1038/bjc.1996.263

23. Hagenaars $M$, Ensink NG, Basse PH, Hokland M, Nannmark U, Eggermont AM, et al. The microscopic anatomy of experimental rat CC531 colon tumour metastases: consequences for immunotherapy? Clin Exp Metastasis (2000) 18:189-96. doi:10.1023/A:1011062002851

24. Rodenbach M, Eyol E, Seelig MH, Berger MR. Combination treatment of CC531-lac-Z rat liver metastases by chemoembolization with pemetrexed disodium and gemcitabine. J Cancer Res Clin Oncol (2005) 131:289-99. doi:10.1007/s00432-004-0643-y

25. Saenger J, Leible M, Seelig MH, Berger MR. Chemoembolization of rat liver metastasis with irinotecan and quantification of tumor cell reduction. J Cancer Res Clin Oncol (2004) 130:203-10. doi:10.1007/s00432-003-0523-x 
26. Seelig MH, Leible M, Sanger J, Berger MR. Chemoembolization of rat liver metastasis with microspheres and gemcitabine followed by evaluation of tumor cell load by chemiluminescence. Oncol Rep (2004) 11:1107-13. doi:10.3892/or.11.5.1107

27. Eyol E, Boleij A, Taylor RR, Lewis AL, Berger MR. Chemoembolisation of rat colorectal liver metastases with drug eluting beads loaded with irinotecan or doxorubicin. Clin Exp Metastasis (2008) 25:273-82. doi:10.1007/ s10585-008-9142-x

28. Lin WC, Pretlow TP, Pretlow TG II, Culp LA. Bacterial lacZ gene as a highly sensitive marker to detect micrometastasis formation during tumor progression. Cancer Res (1990) 50:2808-17.

29. Lin WC, Pretlow TP, Pretlow TG III, Culp LA. Development of micrometastases: earliest events detected with bacterial lacZ gene-tagged tumor cells. J Natl Cancer Inst (1990) 82:1497-503. doi:10.1093/jnci/82.18.1497

30. Brunner N, Thompson EW, Spang-Thomsen M, Rygaard J, Dano K, Zwiebel JA. lacZ transduced human breast cancer xenografts as an in vivo model for the study of invasion and metastasis. Eur J Cancer (1992) 28A:1989-95. doi:10.1016/0959-8049(92)90245-W

31. Kobayashi K, Nakanishi H, Masuda A, Tezuka N, Mutai M, Tatematsu M. Sequential observation of micrometastasis formation by bacterial lacZ gene-tagged Lewis lung carcinoma cells. Cancer Lett (1997) 112:191-8. doi:10.1016/S0304-3835(96)04569-7

32. Culp LA, Lin W, Kleinman NR, O'Connor KL, Lechner R. Earliest steps in primary tumor formation and micrometastasis resolved with histochemical markers of gene-tagged tumor cells. J Histochem Cytochem (1998) 46:557-68. doi:10.1177/002215549804600501

33. Culp LA, Lin WC, Kleinman NR, Campero NM, Miller CJ, Holleran JL. Tumor progression, micrometastasis, and genetic instability tracked with histochemical marker genes. Prog Histochem Cytochem (1998) 33:XI-XV, 329-48. doi:10.1016/S0079-6336(98)80008-9

34. Holleran JL, Miller CJ, Edgehouse NL, Pretlow TP, Culp LA. Differential experimental micrometastasis to lung, liver, and bone with lacZ-tagged CWR22R prostate carcinoma cells. Clin Exp Metastasis (2002) 19:17-24. doi:10.1023/A:1013833111207

35. Kruger A, Schirrmacher V, Khokha R. The bacterial lacZ gene: an important tool for metastasis research and evaluation of new cancer therapies. Cancer Metastasis Rev (1998) 17:285-94. doi:10.1023/A:1006066706040

36. Maurer-Gebhard M, Schmidt M, Azemar M, Stocklin E, Wels W, Groner B. A novel animal model for the evaluation of the efficacy of drugs directed against the ErbB2 receptor on metastasis formation. Hybridoma (1999) 18:69-75. doi:10.1089/hyb.1999.18.69

37. Zhang L, Kharbanda S, Mcleskey SW, Kern FG. Overexpression of fibroblast growth factor 1 in MCF-7 breast cancer cells facilitates tumor cell dissemination but does not support the development of macrometastases in the lungs or lymph nodes. Cancer Res (1999) 59:5023-9.

38. Wittmer A, Khazaie K, Berger MR. Quantitative detection of lac-Z-transfected CC531 colon carcinoma cells in an orthotopic rat liver metastasis model. Clin Exp Metastasis (1999) 17:369-76. doi:10.1023/A:1006643831825

39. van der Wal BC, Hofland LJ, Marquet RL, Van Koetsveld PM, Van Rossen ME, Van Eijck CH. Paracrine interactions between mesothelial and coloncarcinoma cells in a rat model. Int J Cancer (1997) 73:885-90. doi:10.1002/ (SICI) 1097-0215(19971210)73:6<885::AID-IJC21>3.0.CO;2-2

40. Li X, Mortensen B, Rushfeldt C, Huseby NE. Serum gamma-glutamyltransferase and alkaline phosphatase during experimental liver metastases. Detection of tumour-specific isoforms and factors affecting their serum levels. Eur J Cancer (1998) 34:1935-40. doi:10.1016/S0959-8049(98)00196-8

41. Adobati E, Zacchetti A, Perico ME, Cremonesi F, Rasi G, Vallebona PS, et al. Expression profile of saccharide epitope CaMBrl in normal and neoplastic tissue from dogs, cats, and rats: implication for the development of human-derived cancer vaccines. Histochem J (1999) 31:729-37. doi:10.1023/ A:1003900631953

42. Demetrikopoulos MK, Goldfarb RH, Zhang ZB, Weiss JM. Blood level of $\mathrm{B}$ and CD4+ lymphocytes measured before induction of an experimental tumor in rats predicts tumor progression and survival. Cancer Epidemiol Biomarkers Prev (2000) 9:609-17.

43. Isbert C, Ritz JP, Roggan A, Schuppan D, Ruhl M, Buhr HJ, et al. Enhancement of the immune response to residual intrahepatic tumor tissue by laser-induced thermotherapy (LITT) compared to hepatic resection. Lasers Surg Med (2004) 35:284-92. doi:10.1002/lsm.20097
44. Velthuis JH, Gavric Z, De Bont HJ, Nagelkerke JF. Impaired activation of caspases and prevention of mitochondrial dysfunction in the metastatic colon carcinoma CC531s-m2 cell line. Biochem Pharmacol (2005) 69:463-71. doi:10.1016/j.bcp.2004.10.010

45. Sun H, Liu L, Pang KS. Increased estrogen sulfation of estradiol 17beta-Dglucuronide in metastatic tumor rat livers. JPharmacol Exp Ther (2006) 319:818-31. doi:10.1124/jpet.106.108860

46. Bouvet M, Wang J, Nardin SR, Nassirpour R, Yang M, Baranov E, et al. Realtime optical imaging of primary tumor growth and multiple metastatic events in a pancreatic cancer orthotopic model. Cancer Res (2002) 62:1534-40.

47. Georges R, Bergmann F, Hamdi H, Zepp M, Eyol E, Hielscher T, et al. Sequential biphasic changes in claudin1 and claudin4 expression are correlated to colorectal cancer progression and liver metastasis. J Cell Mol Med (2012) 16:260-72. doi:10.1111/j.1582-4934.2011.01289.x

48. Yang M, Baranov E, Jiang P, Sun FX, Li XM, Li L, et al. Whole-body optical imaging of green fluorescent protein-expressing tumors and metastases. Proc Natl Acad Sci U S A (2000) 97:1206-11. doi:10.1073/pnas.97.3.1206

49. Adams JY, Johnson M, Sato M, Berger F, Gambhir SS, Carey M, et al. Visualization of advanced human prostate cancer lesions in living mice by a targeted gene transfer vector and optical imaging. Nat Med (2002) 8:891-7. doi:10.1038/nm743

50. Vooijs M, Jonkers J, Lyons S, Berns A. Noninvasive imaging of spontaneous retinoblastoma pathway-dependent tumors in mice. Cancer Res (2002) 62:1862-7.

51. Sweeney TJ, Mailander V, Tucker AA, Olomu AB, Zhang W, Cao Y, et al. Visualizing the kinetics of tumor-cell clearance in living animals. Proc Natl Acad Sci U S A (1999) 96:12044-9. doi:10.1073/pnas.96.21.12044

52. Georges RB, Adwan H, Hamdi H, Hielscher T, Linnemann U, Berger MR. The insulin-like growth factor binding proteins 3 and 7 are associated with colorectal cancer and liver metastasis. Cancer Biol Ther (2011) 12:69-79. doi:10.4161/cbt.12.1.15719

53. Georges R, Adwan H, Zhivkova M, Eyol E, Bergmann F, Berger MR. Regulation of osteopontin and related proteins in rat CC531 colorectal cancer cells. Int J Oncol (2010) 37:249-56. doi:10.3892/ijo_00000672

54. Speetjens FM, Kuppen PJ, Sandel MH, Menon AG, Burg D, Van De Velde CJ, et al. Disrupted expression of CXCL5 in colorectal cancer is associated with rapid tumor formation in rats and poor prognosis in patients. Clin Cancer Res (2008) 14:2276-84. doi:10.1158/1078-0432.CCR-07-4045

55. Eyol E, Murtaga A, Zhivkova-Galunska M, Georges R, Zepp M, Djandji D, et al. Few genes are associated with the capability of pancreatic ductal adenocarcinoma cells to grow in the liver of nude rats. Oncol Rep (2012) 28:2177-87. doi:10.3892/or.2012.2049

56. Zhivkova-Galunska M, Adwan H, Eyol E, Kleeff J, Kolb A, Bergmann F, et al. Osteopontin but not osteonectin favors the metastatic growth of pancreatic cancer cell lines. Cancer Biol Ther (2010) 10:54-64. doi:10.4161/ cbt.10.1.12161

57. Cano A, Perez-Moreno MA, Rodrigo I, Locascio A, Blanco MJ, Del Barrio $\mathrm{MG}$, et al. The transcription factor snail controls epithelial-mesenchymal transitions by repressing E-cadherin expression. Nat Cell Biol (2000) 2:76-83. doi:10.1038/35010506

58. Chaffer CL, Weinberg RA. A perspective on cancer cell metastasis. Science (2011) 331:1559-64. doi:10.1126/science.1203543

59. Ikenouchi J, Matsuda M, Furuse M, Tsukita S. Regulation of tight junctions during the epithelium-mesenchyme transition: direct repression of the gene expression of claudins/occludin by snail. JCell Sci (2003) 116:1959-67. doi: $10.1242 /$ jcs. 00389

60. Thiery JP. Epithelial-mesenchymal transitions in tumour progression. Nat Rev Cancer (2002) 2:442-54. doi:10.1038/nrc822

61. Akram IG, Georges R, Hielscher T, Adwan H, Berger MR. The chemokines CCR1 and CCRL2 have a role in colorectal cancer liver metastasis. Tumour Biol (2016) 37:2461-71. doi:10.1007/s13277-015-4089-4

62. Pervaiz A, Zepp M, Adwan H, Berger MR. Riproximin modulates multiple signaling cascades leading to cytostatic and apoptotic effects in human breast cancer cells. J Cancer Res Clin Oncol (2016) 142:135-47. doi:10.1007/ s00432-015-2013-3

63. Uhlmann ME, Georges RB, Boleij A, Eyol E, Kubarenko A, Adwan H, et al. Influence of osteopontin expression on the metastatic growth of CC531 rat colorectal carcinoma cells in rat liver. Cancer Gene Ther (2011) 18:795-805. doi:10.1038/cgt.2011.48 
64. Fusai G, Davidson BR. Management of colorectal liver metastases. Colorectal Dis (2003) 5:2-23. doi:10.1046/j.1463-1318.2003.00410.x

65. Leonard GD, Brenner B, Kemeny NE. Neoadjuvant chemotherapy before liver resection for patients with unresectable liver metastases from colorectal carcinoma. J Clin Oncol (2005) 23:2038-48. doi:10.1200/JCO.2005.00.349

66. Fidler IJ. The pathogenesis of cancer metastasis: the 'seed and soil' hypothesis revisited. Nat Rev Cancer (2003) 3:453-8. doi:10.1038/nrc1098

67. Gupta GP, Massague J. Cancer metastasis: building a framework. Cell (2006) 127:679-95. doi:10.1016/j.cell.2006.11.001

68. Radinsky R, Ellis LM. Molecular determinants in the biology of liver metastasis. Surg Oncol Clin N Am (1996) 5:215-29.

69. Billingsley KG, Burt ME, Jara E, Ginsberg RJ, Woodruff JM, Leung DH, et al. Pulmonary metastases from soft tissue sarcoma: analysis of patterns of diseases and postmetastasis survival. Ann Surg (1999) 229:602-10; discussion 610-2. doi:10.1097/00000658-199905000-00002

70. Hess KR, Varadhachary GR, Taylor SH, Wei W, Raber MN, Lenzi R, et al. Metastatic patterns in adenocarcinoma. Cancer (2006) 106:1624-33. doi:10.1002/ cncr. 21778
71. Chiang AC, Massague J. Molecular basis of metastasis. N Engl J Med (2008) 359:2814-23. doi:10.1056/NEJMra0805239

Conflict of Interest Statement: The authors declare that the research was conducted in the absence of any commercial or financial relationships that could be construed as a potential conflict of interest.

The reviewer, WW, and the handling editor declared their shared affiliation, and the handling editor states that the process nevertheless met the standards of a fair and objective review.

Copyright (c) 2017 Adwan, Georges, Pervaiz and Berger. This is an open-access article distributed under the terms of the Creative Commons Attribution License (CC BY). The use, distribution or reproduction in other forums is permitted, provided the original author(s) or licensor are credited and that the original publication in this journal is cited, in accordance with accepted academic practice. No use, distribution or reproduction is permitted which does not comply with these terms. 